\title{
ESTRATÉGIAS DE COMUNICAÇÃO E MÍDIAS SOCIAIS DIGITAIS: ESTUDO DE CASO DE UMA EMPRESA DO VAREJO DE MÉDIO PORTE
}


ESTRATÉGIAS DE COMUNICAÇÃO E MÍDIAS SOCIAIS DIGITAIS: ESTUDO DE CASO DE UMA EMPRESA DO VAREJO DE MÉDIO PORTE

Resumo: Este estudo analisa a inserção da empresa Eny Calçados no âmbito digital, empregando as mídias sociais digitais como estratégia de comunicação para manter uma relação mais próxima com os públicos. A pesquisa é de caráter exploratório e descritivo e a abordagem metodológica de natureza qualitativa, tendo como instrumento de coleta de dados uma entrevista em profundidade. Palavras chave: estratégias de comunicação; mídias digitais, mídias sociais digitais, redes sociais digitais

ESTRATEGIAS DE COMUNICACIÓN Y MEDIAS SOCIALES DIGITALES:

ESTUDIO DE CASO DE UNA EMPRESA DE VENTAS POR MENOR DE MEDIO PORTE

Resumen: Este estudio analiza la inserción de la empresa Eny Calçados en el ámbito digital, empleando las medios sociales digitales como estrategia de comunicación para mantener una relación más próxima con los públicos. La investigación es de naturaleza exploratoria y descriptiva y el abordaje metodológico es cualitativo, teniendo como instrumento de coleta de datos una entrevista en profundidad.

Palabras clave: estrategias de comunicación; medios digitales; medios sociales digitales; redes sociales digitales

COMMUNICATION STRATEGIES AND DIGITAL SOCIAL MEDIA: CASE OF STUDY OF A COMPANY OF THE MIDSIZE RETAIL

Abstract: This study analizes the inserction of the company Eny Calçados in the digital, using digital and social media as strategy of communication to maintain a closer relationship with the public. The research is exploratory and descriptive and the metodological approach is qualitative, having as a data collection instrument an interview in depth.

Keywords: Communication strategies; digital media; digital social media; digital social networks 


\section{CONSIDERAÇÕES INICIAIS}

As empresas têm utilizado as ferramentas digitais como uma alternativa para criar vínculo, estabelecer comunicação e interação de maneira direta, instantânea e difusa na mensagem compartilhada com os públicos de interesse. A evolução das tecnologias proporcionou várias maneiras de se estabelecer um espaço de comunicação e as organizações estão aprendendo sobre essas tendências e sobre as possibilidades de explorar o que as novas dinâmicas de relacionamento prometem.

De acordo com uma pesquisa divulgada pelo Ibope Nielsen Online (2011), 77,8 milhões de brasileiros tem acesso à internet, sendo que $87 \%$ desses internautas estão presentes em redes sociais, consolidando o Brasil como o país com mais usuários nesse segmento. Dados que confirmam que a inserção em mídias sociais digitais e redes sociais digitais passaram a configurar-se em um fator decisivo na comunicação da empresa. Muitos usos criativos dessas ferramentas tais como vídeos de interação com os consumidores, perfis com aplicativos interativos e promoções específicas têm sido realizadas. Diante dessas considerações, surge o questionamento da pesquisa que norteia este estudo: "Quais os resultados que uma empresa varejista de médio porte tem ao se inserir em mídias e redes sociais digitais?"

Com o objetivo geral de mensurar os benefícios que as mídias digitais proporcionam, através das novas tecnologias, para uma empresa de médio porte do varejo calçadista, buscou-se estabelecer quatro objetivos específicos, sendo eles: 1) Identificar quais as mídias sociais digitais e redes sociais digitais que a organização utiliza; 2) Verificar o motivo da opção pelo uso em cada situação; 3) Verificar o feedback do público-alvo em cada um desses espaços digitais; 4) Propor novas formas de inserção na web para a empresa.

Este trabalho poderá servir de ferramenta de pesquisa para outras empresas que têm interesse em participar da web e, ainda, evidenciar os benefícios que uma empresa do varejo de médio porte tem ao se inserir em mídias e redes sociais digitais.

\section{MÍDIAS SOCIAIS E REDES SOCIAIS DIGITAIS VERSUS POSSIBILIDADES DE COMUNICAÇÃO}

Caracterizada como uma ferramenta, desde sua criação, existe duas carac- 
terísticas que fazem da internet uma opção estratégica importante: interatividade e conectividade. De acordo com Zilber (2006, p. 83), "a interatividade tem suas raízes na teoria da informação e da comunicação, podendo ser resumido na assertiva: Quem diz o quê, para quem, em que canal e com que efeito". De acordo com Morais (2009), além de ser um excelente canal de interação com o consumidor, a internet é uma ótima oportunidade para a divulgação da marca, já que o alcance é bem maior do que nos outros meios de comunicação.

Outra característica relevante é "o modo de organização e acesso de informações da internet, o hipertexto [...], onde em uma estrutura hipertextual, o usuário não tem o compromisso de seguir a ordem 'começo, meio e fim', podendo traçar a sua ordem particular." (MONTEIRO, 2001, p. 30) Assim, a internet é mais uma forma que as empresas têm de estabelecer contato com o público, não sendo o único meio para isso, mas, podendo usufruir de suas características para difundir suas mensagens para uma audiência numerosa, heterogênea, dispersa geograficamente e anônima (MONTEIRO, 2001). De acordo com Cavallini (2009) é preciso pensar na internet como sendo uma ferramenta voltada para vários nichos, com várias possibilidades de comunicação e com poucas limitações.

As empresas buscam, além da disseminação da informação, uma interação com o público, e por isso é possível classificar os processos interativos mediados por computador, em dois grandes grupos: o primeiro é a interação reativa, que "caracteriza-se pelas trocas mais automatizadas, processos de simples ação e reação”. Já o segundo grupo, interação mútua, “é baseado na construção cooperativa da relação, cuja evolução repercute nos eventos futuros" (PRIMO, 2009, p. 21).

Aos poucos, as trocas de informações e a interação regida por elas, foram ganhando agilidade pela estabilidade da tecnologia digital, que se tornou uma das principais ferramentas utilizadas para o desenvolvimento da administração de marcas (PRIMO, 2009). Hoje, essa tecnologia está bastante presente no âmbito online (internet), havendo possibilidade de contato direto entre o cliente e a empresa através das ferramentas disponíveis, visto que

a Internet é reconhecidamente uma ferramenta tecnológica estratégica, que deve ser incorporada aos negócios tradicionais, visando obter ou reforçar vantagens competitivas [...], e ao mesmo tempo introduzir inovações nos processos tradicionais (OZAKI, 2010, p.1).

Pela utilização dessa tecnologia, empregada como instrumento de comuni- 
cação, as empresas estão introduzindo inovações e criações de negócios diferenciados que, para Ferreira (2002), servem como grande atrativo ao público. Assim,

a Internet passa a ser uma ferramenta importante para a comunicação integrada de marketing (CIM), principalmente para atingir os segmentos de consumidores mais inovadores, que valorizam a internet e a utilizam como veículo de informação, comunicação, expressão e construção de relacionamentos (OGDEN E CRESCITELLI, 2007, p.101).

É preciso que a empresa insira a sua marca nas ferramentas disponíveis na internet de maneira coerente, unindo as características de cada rede com a intenção de utilização.

Para Recuero (2009, p.24), a internet trouxe várias mudanças à sociedade e a mais significativa é a "possibilidade de expressão e sociabilização através das ferramentas de comunicação mediada pelo computador”. Através dessas possibilidades o consumidor está assumindo um caráter privilegiado, em que ele escolhe o que quer ver, quando e de que maneira quer ver. Por sua vez, completa Leal (2011, p.78) "o uso corporativo das redes sociais cresce de maneira exponencial, pequenas e grandes empresas descobriram uma maneira fácil e barata de se relacionar com os consumidores".

\section{AS REDES SOCIAIS E SEUS USOS}

O Facebook é uma rede' que surgiu da ideia de trocar informações sobre a vida universitária dos acadêmicos de Harvard na internet, havendo troca de fotografias, mensagens e vídeos entre os próprios alunos. No Brasil, a rede surgiu em 2005 e tem hoje 25 milhões de usuários (REVISTA EXAME, 2011). De acordo com Telles (2010, p.79), "o Facebook é uma das maiores redes sociais do mundo e vem crescendo muito no Brasil junto às classes A e B". Há bases potenciais de marketing no Facebook que podem ser exploradas pelas empresas, sendo essas: criação de um perfil (mostra sua presença na rede e é a página mais procurada em pesquisas on-line); promoção de eventos (leva notícias da empresa para o público); envio de mensagens (funciona muito bem para conseguir contato com o público de interesse); realização de pesquisas (é possível realizar pesquisa de mercado com seu público-alvo através dessa oferta); participar

1 Disponível em: <www.facebook.com> 
de grupos pertinentes (é válido usar esse recurso para entrar em contato com o público); criar um grupo para seu negócio (praticamente a criação de uma comunidade em torno da marca da empresa); atribuir uma agência digital para cuidar da sua página (para manter a página atualizada); criar uma estratégia de marketing (para atrair fãs para a página) e promover sua página (usar uma integração entre as redes, divulgando a página da empresa).

O Twitter ${ }^{2}$, por sua vez, foi criado, em 2006, com a ideia de que os funcionários pudessem usar um serviço de troca de status. Assim como SMS (mensagem via celular), por meio de mensagens curtas enviadas através do celular, as outras pessoas que estivessem conectadas ao serviço, receberiam um twich (vibração, em tradução livre) no seu bolso quando um update fosse enviado. Considerado um microblogging, o Twitter, permite que, em textos de apenas 140 caracteres, o usuário responda a pergunta: “O que você está fazendo?”. Atualmente o Twitter é uma das ferramentas de comunicação mais utilizada pelas empresas brasileiras que se inserem na web em busca de interatividade, objetividade e alcance. Postando fotos, vídeos, informações sobre a marca, sobre o segmento que atuam, divulgando promoções relâmpagos, dentre outras opções, os perfis das empresas brasileiras estão cada vez chamando mais atenção do consumidor.

O Blog corporativo, escreve Ivo (2010, p.1), "embora não seja exatamente uma rede social e esteja mais para uma mídia social, um blog corporativo é parte fundamental de estratégias em redes sociais". Mantido por uma empresa, é possível detalhar os serviços prestados ou produtos vendidos, divulgar notícias da própria marca ou do mercado e ter um canal de comunicação direta com o público.

Optando por uma ou outra rede, é importante que a marca não busque apenas a sua inserção nas mídias sociais digitais, mas que mantenha atualizado todo o conteúdo, mostrando para os internautas que está presente de forma efetiva, postando atualizações diárias e fazendo manutenção constante de sua imagem.

Existem várias diferenças entre o ambiente offline e o ambiente online, assim, o conteúdo gerado em cada um deles, bem como a maneira como será transmitido ao público, precisa ser adaptado de acordo com suas características. Cuidar da imagem da marca na web é um trabalho desafiador e é preciso planejar os conteúdos de relevância.

E mais, considerando que a internet possibilita liberdade às pessoas e, 
como produtoras de conteúdos, elas podem fazer comentários negativos a respeito da empresa, é preciso que haja um profissional responsável pela gestão e manutenção dos conteúdos relacionados à marca na web. Já é possível que a empresa adquira um gerenciador de conteúdo³ para fazer essa manutenção, permitindo gerenciar e aperfeiçoar os fluxos de trabalho da organização.

Tanto no mundo real, quanto no mundo virtual, é preciso destacar que tudo o que é feito nas empresas, é feito de pessoas para pessoas, por isso, é importante ter equipes de qualidade envolvidas nos processos mercadológicos e comunicacionais. A diferença será percebida e valorizada pelo consumidor final, que dará mais atenção para a sua empresa do que para a concorrência (MARTINS, 2006).

\section{METODOLOGIA}

A presente pesquisa se concentra no estudo e compreensão das utilizações das mídias sociais digitais como ferramentas de comunicação por uma empresa de médio porte do varejo de calçados. Trata-se de uma pesquisa qualitativa, que

[...] situa, geralmente, sua contribuição à pesquisa social, na renovação do olhar lançado sobre os problemas sociais e sobre os mecanismos profissionais e institucionais de sua gestão. Visando à modificação da percepção dos problemas e também da avaliação dos serviços, a pesquisa qualitativa pretende mudar tanto a prática, quanto seus modos de gestão (GROULX, 2010, p.96).

A pesquisa é considerada qualitativa, pois há uma interpretação lógica dos fenômenos, assim, Fachin (2003, p.81) explica que "a pesquisa é caracterizada pelos seus atributos e relaciona aspectos não somente mensuráveis, mas também definidos descritivamente."

Para alcançar os objetivos propostos neste trabalho, a primeira etapa utilizou-se de uma pesquisa bibliográfica, que, de acordo com Gil (2006, p. 65) “é desenvolvida a partir de material já elaborado, constituído principalmente de livros e artigos científicos", a fim de se obter um embasamento teórico apro-

3 É uma ferramenta que permite integrar e automatizar todos os processos relacionados à criação, catalogação, indexação, personalização, controle de acesso e disponibilização de conteúdos em portais web. Disponível em: <http://www.paradigma.com.br/leiamais/leiamais0005/view> Acesso em: maio 2011. 
fundado que auxilie no desenvolvimento do estudo. Além disso, utilizou-se uma pesquisa de nível exploratório, e descritiva, tendo como objetivo realizar o levantamento de informações sobre as ferramentas de relacionamento na internet e empresas que se inserem nas redes sociais digitais a fim de aproximar sua marca do público.

No caso deste artigo, foi realizado um estudo de caso por que além de permitir ao pesquisador o acompanhamento e a proximidade com um fenômeno da mídia contemporânea, é também, de acordo com Yin (2001, p.19), "uma inquirição empírica que investiga um fenômeno contemporâneo dentro de um contexto da vida real, quando a fronteira entre o fenômeno e o contexto não é claramente evidente e onde múltiplas fontes de evidência são utilizadas."

$\mathrm{Na}$ fase inicial foi feito levantamento bibliográfico, que tem como propósito "identificar informações e subsídios para definição dos objetivos, determinação do problema e definição dos tópicos do referencial teórico" (MICHEL, 2009, p. 40). Na segunda etapa, partiu-se para a observação, que de acordo com Jaccoud (2010, p. 255) "coloca no centro de seu objeto de estudo, não fatos constituídos, mas sim ações coletivas e processos sociais que podem ser em parte apreendidos por meio de interações diretas, cuja significação - cabe não negligenciar - não é determinada previamente".

Uma entrevista em profundidade com o profissional responsável pela gestão de conteúdo da marca na web esclareceu questões relacionadas às mídias e redes sociais digitais em que a empresa está inserida. Na quarta etapa, e última, foi feita uma análise de relatórios da empresa sobre as redes e feedback existente com o público, para então apresentar as sugestões de novas inserções para a empresa.

\section{A ENY CALÇADOS INSERIDA NO ÂMBITO DIGITAL DA COMUNICAÇÃO}

Criada em 19244, a empresa de origem familiar, conquistou tradição no mercado calçadista de Santa Maria e região. Somando um total de 14 lojas, situadas nas cidades de Santa Maria (RS), Santa Cruz do Sul (RS), Cachoeirinha (RS) e Porto Alegre (RS), a empresa conta com 350 funcionários, tendo venda anual

4 As informações deste capítulo foram retiradas do site da empresa Eny Calçados. Disponível em: <http://eny.com.br/novo_site/index.php?MODULE=descricao_menu\&COD_MENU=033> Acesso em: 10 maio 2011. 
de aproximadamente 800 mil pares de calçados.

Muller e Machado (2010) constataram através da observação de práticas comunicacionais da Eny, que há uma predisposição da empresa em trabalhar com mídias de massa, uma vez que o público de interesse são as classes C e D. De acordo com Machado (2011),

Boa parte do público que acessa a internet é o mesmo que vai às lojas sim, mesmo não tendo retorno pela internet nas pesquisas de satisfação de público, realizado nas lojas, o pessoal aponta o site e alguns perfis da empresa. Pelo menos conhece, mesmo que não tenha interagido alguma vez. Ainda não sabemos o número exato de quem frequenta as lojas em função das redes sociais, nem a conversão em vendas motivadas pela nossa presença digital.

Os anúncios em rádio $\mathrm{AM}$ e $\mathrm{FM}$ e televisão são bastante utilizados, justamente pela visibilidade do público-alvo. A partir do final dos anos 90, as ações em ponto de venda (PDV) e adesivação de vitrines também passam a ser bastante utilizadas como mais um diferencial para também atrair a atenção do público. O potencial das mídias digitais foi percebido em 1997, quando lançaram o site institucional da empresa. E, em 2010, efetivamente, as ações referentes à interação e relacionamento com o público através da internet acabaram sendo planejados. Neste período foi criado um núcleo de comunicação digital junto ao departamento de comunicação.

Desde o final de 2009, a empresa começou a investir na comunicação/relação online com seus clientes, pois se acredita que a marca pode ser falada, citada, comentada na web sem ser uma fonte institucional (MACHADO, 2011). Ainda, para Machado (2011), a única estratégia para atrair a atenção do público é a postagem de conteúdos relevantes, focado nos interesses dessas pessoas. As ações de comunicação realizadas nas mídias sociais digitais, além da produção de conteúdo e postagem, é o relacionamento com fornecedores, com blogueiras de moda e esporte, interação com o público de interesse, disponibilização de vídeos e fotografias, informações sobre cultura e entretenimento local e, recentemente, um blog focado no público feminino.

A Eny Calçados está inserida em 5 mídias sociais digitais, sendo elas: página institucional no facebook, perfil no twitter, formspring, canal no Youtube, e blog. Para manter a atualização constante dos perfis, há um planejamento no final de cada ano para as ações em mídias digitais, que contempla também as ações de 
marketing. As postagens são planejadas também levando em conta as datas comemorativas, feedback do público e insights a partir de mapeamento na internet. O feedback com o público das mídias sociais digitais, de acordo com Machado (2011), é mais eficiente no facebook e no twitter e isso é analisado através das respostas, RT's ${ }^{5}$, curtidas ${ }^{6}$ na página, comentários no facebook, replies no twitter, postagens no mural do facebook, pessoas que indicam que outros usuários sigam o perfil da empresa. Para ele, há dificuldades encontradas nas plataformas,

No Facebook há limitação de visibilidade, eu acredito, pelo fato de não poder acessar os perfis das pessoas por completo, não tem como escrever no mural das pessoas, por exemplo. A newsletter é uma dificuldade porque o conteúdo pode não ser relevante para todos os cadastrados. O portal institucional é o menos problemático porque somos nós quem gerimos a plataforma. O Orkut, pelo fato dos spams, que não acrescentam em nada nas relações, as estratégias acabam sendo poucas sendo postagem de vídeos, fotos, parabenização, participação em comunidade de acordo com os interesses da empresa e a ferramenta "Promova", que usamos para divulgar promoções. No Twitter, a dificuldade é tentar focar mais no público que realmente é fiel do que aqueles que estão atrás apenas de promoções (MACHADO, 2011).

Machado (2011) exemplifica que "quando alguém busca trabalho ou produto, o primeiro lugar que vão é a internet e se a gente não estiver ali com uma presença marcada e bem posicionada com relação à visão, missão e valores da empresa, ficaremos fora deste mercado e deste contexto." Mesmo com a tradição, a inserção no meio, segundo Machado, é para ter conhecimento das novidades que

A empresa, mesmo tradicional, teve que se adaptar e entrar nessa ambiência justamente para suprir a necessidade de alguns clientes, por exemplo, clientes que antes de ir até a loja para efetuar a compra, vão até a internet para buscar informações sobre determinado produto. E também é uma questão de dar visibilidade ao nome da empresa, assim como, seus projetos, ações e produtos (MACHADO, 2011).

Quanto à perspectiva de ampliação do trabalho realizado, Machado (2011)

5 Quando algum usuário compartilha a mensagem passada pela empresa, divulgando-a, assim, para mais pessoas.

6 Quando algum usuário identifica-se com alguma marca, pode curtir a página empresarial desta empresa como forma de mostrar que gosta do produto/serviço oferecido. 
diz que será feita uma análise se o público que a empresa atinge está entrando nesses espaços para que seja possível acompanhá-lo. As perspectivas de mais investimentos nas mídias sociais digitais são concretas, pois a internet está sempre se reconfigurando e é preciso acompanhá-la para estar presente onde o público-alvo está. Para saber o que os consumidores andam postando sobre a marca na web, são utilizadas ferramentas de monitoramento, tais como: Google, Bing e Yahoo (busca mecânica), Twitter e Facebook (busca mecânica), Google Analytics (relatório do site com gráficos), Twitoria (contatos que não tuitam por longo período de tempo), Friend or Follow (quem você segue, mas que não te segue), Real Time Search (menções em blogs, YouTube e Picasa), Qwitter (quem deixa de nos seguir), Twitter Search (buscador de palavras-chave no twitter), Google Alertas (alertas de menções por e-mail), Google Trends (comparação de termos: contexto), Reclame Aqui (site de reclamação de consumidores) e o E-life Facebook Search (buscador de palavras-chave no Facebook). Neste artigo, será analisado o blog da empresa, o twitter e a fanpage no Facebook.

O blog da Eny Calçados foi ao ar dia $1^{\circ}$ de agosto de 2011 com o nome "De Par com a Moda"'. Preocupados em dar um caráter mais profissional à mídia, a responsável pelas atualizações é uma profissional formada em Design de Produto, especialista em Design de Estamparia, tendo estudado Design de Moda na Itália. Com duas atualizações semanais, os posts variam sobre o assunto abordado, mas apresentam como característica comum o uso de bastantes imagens que servem de apoio ao texto. Durante o período analisado foram feitas 9 postagens (Tabela 1), sendo, na sua maioria, sobre bolsas e sapatos que seriam tendências no verão 2012.

Tabela 1: Posts blog “De Par com a Moda”.

\begin{tabular}{|l|l|l|}
\hline DATA & TÍTULO & ASSUNTO \\
\hline 22 de agosto de 2011 & $\begin{array}{l}\text { Já pro closet! Bolsa e ox- } \\
\text { ford Capodarte }\end{array}$ & $\begin{array}{l}\text { Divulgação de uma linha de pro- } \\
\text { dutos comercializada pela loja, } \\
\text { com quatro fotos que servem de } \\
\text { apoio ao texto. }\end{array}$ \\
\hline 25 de agosto de 2011 & $\begin{array}{l}\text { Trends Verão 2012: “O que } \\
\text { é que a baiana tem?” }\end{array}$ & $\begin{array}{l}\text { Alusão à música de Carmem Mi- } \\
\text { randa e ao uso das sandálias pla- } \\
\text { taformas no verão. }\end{array}$ \\
\hline
\end{tabular}

7 http://enycalcados.blogspot.com/ 


\begin{tabular}{|l|l|l|}
\hline 29 de agosto de 2011 & No balanço do mar... & $\begin{array}{l}\text { Referência dos sapatos estilos } \\
\text { marinheiros, pelas cores e carac- } \\
\text { terísticas. }\end{array}$ \\
\hline 01 de setembro de 2011 & Excentricidades... & $\begin{array}{l}\text { Modelo de uma sapatilha de balé } \\
\text { com salto, do designer Christian } \\
\text { Louboutin. }\end{array}$ \\
\hline 05 de setembro de 2011 & $\begin{array}{l}\text { Anabelas: uma das gran- } \\
\text { des apostas do Verão 2012 }\end{array}$ & $\begin{array}{l}\text { Fotografias com sapatos do estilo } \\
\text { Anabela. }\end{array}$ \\
\hline 08 de setembro de 2011 & $\begin{array}{l}\text { Trends Verão 2012: Color } \\
\text { Blocking }\end{array}$ & $\begin{array}{l}\text { A tendência do Color Blocking } \\
\text { também está presente em sapa- } \\
\text { tos e bolsas. }\end{array}$ \\
\hline 12 de setembro de 2011 & $\begin{array}{l}\text { Sapateiros Superstars: Ni- } \\
\text { cholas Kirkwood }\end{array}$ & $\begin{array}{l}\text { Apresentação do designer britâ- } \\
\text { nico e de seus modelos criativos } \\
\text { de sapatos. }\end{array}$ \\
\hline 15 de setembro de 2011 & Sapatilhas verão 2012 & $\begin{array}{l}\text { Dica de modelo de sapato para } \\
\text { usar no verão. }\end{array}$ \\
\hline 19 de setembro de 2011 & $\begin{array}{l}\text { Espadrilles: uma das gran- } \\
\text { des apostas do Verão 2012 }\end{array}$ & $\begin{array}{l}\text { Post que diz que espadrilles são } \\
\text { as grandes sensações do verão } \\
2012 .\end{array}$ \\
\hline
\end{tabular}

Fonte: elaborada pelas autoras

De 20 de agosto a 20 de setembro, houve 23 novos seguidores e um total de 263 visualizações do blog, que tiveram como origens de tráfego o site de buscas Google, Facebook, Twitter e o site institucional da própria empresa. Durante esse período compreendido, o "De Par com a Moda" recebeu 05 comentários positivos e nenhum negativo, mostrando que o blog está tendo boa repercussão entre o público, mas que ainda precisa mais divulgação.

A página da Eny Calçados no Facebook é atualizada diariamente, havendo postagens de conteúdos referentes aos produtos comercializados nas lojas e ações que estão sendo realizas no período. Durante o período observado, de 20 de março a 20 de setembro, a página da empresa contava com 129 curtidas (na figura acima mostrada o número de curtidas está maior, pois o print da página foi feito após o período de análise); 232 curtidas em posts escritos na página e 13 curtidas em posts compartilhados pela página. Houve 30 comentários relativos a essas atualizações e 16 compartilhamentos do conteúdo (Tabela 2).

A conta empresarial da Eny é vinculada com o Twitter da mesma, que, automaticamente, redireciona todos tweets escritos para a página. Além desse 
vínculo, há também o atalho interligado ao canal Youtube da Eny Calçados, também atualizando, automaticamente, toda vez que um vídeo for inserido. As 143 fotos publicadas no perfil também são um atrativo, pois através delas são divulgadas as ações, os produtos, os atendentes, o interior das lojas, entre outros. O layout personalizado, com texto que contém gírias da própria rede, é mais um diferencial que atribui um caráter corporativo e inovador à empresa.

Tabela 2: Exemplos de comentários e posts compartilhados e curtidos.

\begin{tabular}{|c|c|c|c|}
\hline DATA & COMENTÁRIOS & ASSUNTO POST CURTIDO & $\begin{array}{l}\text { NÚMERO } \\
\text { COMPARTILHAR }\end{array}$ \\
\hline $\begin{array}{l}21 \text { de março de } \\
2011\end{array}$ & - & $\begin{array}{l}1 \text { curtida - Banner virtual con- } \\
\text { curso fotográfico "Click de } \\
\text { páscoa Eny" }\end{array}$ & c \\
\hline $\begin{array}{l}28 \text { de abril de } \\
2011\end{array}$ & $\begin{array}{l}\text { O post recebeu } 7 \\
\text { comentários posi- } \\
\text { tivos }\end{array}$ & $\begin{array}{l}13 \text { curtidas - Banner virtual } \\
\text { "Dê uma curtida na página da } \\
\text { Eny Calçados e concorra a um } \\
\text { par de ingressos para o show } \\
\text { da Pouca Vogal" }\end{array}$ & - \\
\hline $\begin{array}{l}25 \text { de julho de } \\
2011\end{array}$ & - & $\begin{array}{l}3 \text { curtidas - Convite para par- } \\
\text { ticipar do "Concurso Cultural } \\
\text { ao Pé da Letra" }\end{array}$ & 1 compartilhamento \\
\hline $\begin{array}{l}11 \text { de agosto de } \\
2011\end{array}$ & $\begin{array}{l}\text { O post recebeu } 2 \\
\text { comentários posi- } \\
\text { tivos }\end{array}$ & $\begin{array}{l}4 \text { curtidas - Divulgação do } \\
\text { blog “De Par com a Moda" }\end{array}$ & - \\
\hline $\begin{array}{l}09 \text { de setem- } \\
\text { bro de } 2011\end{array}$ & $\begin{array}{l}\text { O post recebeu } \\
1 \quad \text { comentário } \\
\text { positivo }\end{array}$ & $\begin{array}{l}1 \text { curtida Divulgação das ins- } \\
\text { crições do Circuito Junior da } \\
\text { Eny }\end{array}$ & 1 compartilhamento \\
\hline
\end{tabular}

Fonte: Elaborada pelas autoras

Assim como as outras redes, o Twitter da Eny também é focado para a divulgação de produtos e ações da empresa, adaptando o conteúdo ao formato da plataforma. A mídia social talvez seja a que mais ofereça dinâmica, interatividade e simultaneidade na relação empresa/cliente e por isso é, depois do site, a mídia onde o contato com o público seja mais intenso.

Além das mensagens que a própria Eny veicula, também tem o costume de retuitar (rt) tweets de perfis corporativos de fornecedores, clientes e colaboradores. Todas as mensagens têm como característica apresentar conteúdo referente à moda, esporte, sapatos e novidades/entretenimento na cidade de Santa 
Maria e região. O feedback entre a Eny e seus seguidores no Twitter é bastante efetivo visto que os números apresentados a seguir mostram que há bastante participação dos usuários com a empresa (Tabela 5). De acordo com Machado (2011), no caso do Twitter "a maior dificuldade é tentar focar mais no público que realmente é fiel do que aqueles que estão atrás apenas de promoções."

Tabela 3: Exemplos de tweets e menções do Twitter @EnyCalcados

\begin{tabular}{|c|c|}
\hline $\begin{array}{l}\text { MENSAGENS ENVIADAS PELA @ } \\
\text { ENYCALÇADOS }\end{array}$ & MENÇÖES \\
\hline $\begin{array}{l}\text { Nosso @RiograndenseFC } \\
\text { vence Três Passos por 2xo. Ingres- } \\
\text { sos p/ os próximos jogos à venda } \\
\text { na Eny Pro,Stadium e Esportes. }\end{array}$ & $\begin{array}{l}\text { @bourbonshopping } \\
\text { Click de Páscoa é o concurso fotográfico da @Eny- } \\
\text { Calcados saiba como participar e aparecer na vitrine } \\
\text { da loja }\end{array}$ \\
\hline $\begin{array}{l}\text { Parabéns às blogueiras de moda e } \\
\text { aos blogueiros esportivos que nos } \\
\text { acompanham! > > \#diadobloguei- } \\
\text { ro }\end{array}$ & $\begin{array}{l}\text { @Julirosa } \\
\text { Achei coisa mais querida as vitrines da @enycalca- } \\
\text { dos com as crianças. Coisa mais amor!! :D }\end{array}$ \\
\hline $\begin{array}{l}\text { Envie-nos um tweet até às } 18 \mathrm{~h} \\
\text { dizendo por que você merece ga- } \\
\text { nhar a camisa do @Riograndense- } \\
\text { FC A melhor resposta leva! \#Cora- } \\
\text { çãoVerdeaBater }\end{array}$ & $\begin{array}{l}\text { @royalplazasm } \\
\text { De Par com a Moda, o Blog da Eny. Acompanhe no- } \\
\text { vidades em desing, sapatos, estilistas e tendências, } \\
\text { com Natalia Isaia.enycalcados.blogspot.com }\end{array}$ \\
\hline $\begin{array}{l}\text { No próximo domingo, dia 3, nos- } \\
\text { sas lojas em Santa Maria abrirão } \\
\text { das 14h às 19h e a Eny no @bour- } \\
\text { bonshopping, em Porto Alegre, } \\
\text { das 14h às 20h }\end{array}$ & $\begin{array}{l}\text { @texjunior } \\
\text { Os textos selecionados para a 2a ed. do livro “Ao pé } \\
\text { da letra” das lojas @EnyCalcados .. bit.ly/qIQIhl }\end{array}$ \\
\hline $\begin{array}{l}\text { Uma boa sexta-feira a todos! Apro- } \\
\text { veitem e confiram as novidades da } \\
\text { nossa Vitrine Virtual >>> http://mi- } \\
\text { gre.me/4flgy\#BomDia }\end{array}$ & $\begin{array}{l}\text { @Monet_Shopping } \\
\text { Faça parte da } 2^{\text {a }} \text { edição do livro Ao Pé da Letra. Escre- } \\
\text { va seu texto e participe! migre.me/5aFZO \#Concurso- } \\
\text { Cultural \#FundaçãoEny }\end{array}$ \\
\hline $\begin{array}{l}\text { Desejamos um Feliz Dia das Mães, } \\
\text { às Mães nossas seguidoras, às } \\
\text { Mães de coração, a todas sem ex- } \\
\text { ceção! Parabéns!!! \#felizdidasma- } \\
\text { es }\end{array}$ & $\begin{array}{l}\text { @Natalialsaia } \\
\text { Meias-calças para o inverno! Que tal meia-calça de } \\
\text { oncinha? Sugestões da @Carrano_direto da vitrine } \\
\text { da @EnyCalcados! }\end{array}$ \\
\hline $\begin{array}{l}\text { A Eny tem orgulho de sua origem } \\
\text { gaúcha. Há } 87 \text { anos, investimos } \\
\text { no Rio Grande do Sul acreditando } \\
\text { sempre no potencial da gente des- } \\
\text { ta terra! }\end{array}$ & $\begin{array}{l}\text { @Natalialsaia } \\
\text { Hoje tem sorteio no De Par com a Moda da@EnyCal- } \\
\text { cados! É só ser seguidor do blog para concorrer!ht- } \\
\text { tp://enycalcados.blogspot.com/ }\end{array}$ \\
\hline
\end{tabular}

Fonte: Elaborada pelas autoras 
Durante o período analisado, os seguidores deram 203 RT's nas mensagens publicadas pelo perfil da empresa, responderam 63 mensagens e enviaram 15 mensagens diretas. O perfil é seguido por 861 usuários e segue 906, totalizando 45 pessoas a serem seguidas e não seguindo. Não existem metas planejadas a serem cumpridas em cada mídia, mas no Twitter, por exemplo, é habitual haver, no mínimo, 2 tweets (mensagens) por dia.

\section{CONSIDERAÇÕES FINAIS}

O presente trabalho procurou responder quais os resultados que uma empresa varejista tem ao se inserir em mídias e redes sociais digitais e teve como objetivo principal mensurar os benefícios que as mídias digitais proporcionam para uma empresa de médio porte do varejo de calçados.

Através dessa pesquisa foi possível verificar que uma empresa, mesmo apresentando características tradicionais e familiares, quando está decidida a estreitar o relacionamento com o consumidor, consegue alternativas comunicacionais bastante efetivas para esse processo. Com o investimento em um departamento que conta com profissionais comprometidos com a divulgação da marca na web, é possível observar que o feedback acontece de maneira quase instantânea.

É importante que a Eny Calçados esteja sempre presente nas mais diversas formas de contato com o público externo, assim como, com o público interno, acompanhando a mudanças nas formas de comunicação e crescendo juntamente com as ferramentas que proporcionam uma interação mais simultânea sem haver a necessidade do contato físico.

O principal objetivo da empresa ao se inserir nas mídias sociais é manter um relacionamento estreito com o público, mas também, através de ações realizadas, trazer para dentro das lojas físicas, espalhadas em quatro cidades do Rio Grande do Sul, possíveis consumidores potenciais. O planejamento anual feito para traçar as estratégias e táticas para o cumprimento dessa função é de suma importância visto que assim, o investimento gerará mais vendas de produtos.

Os objetivos específicos propostos neste trabalho também foram respondidos, tendo sido feita a identificação das mídias sociais digitais e redes sociais digitais que a organização utiliza; a verificação do motivo pelo uso em cada situação foi respondido na análise individual de cada mídia; durante o período de observação, 20 de março a 20 de setembro, foi possível verificar o feedback existente do público-alvo em cada ferramenta utilizada e concluiu-se com seis 
sugestões de novas inserções para a empresa Eny Calçados.

Pode-se avaliar, então, por meio de todas as análises feitas que todas as ferramentas utilizadas pela organização respondem com eficácia aos objetivos de inserção, tendo a participação do público e estabelecendo uma relação efetiva com todos os internautas presentes que estão vinculados as suas contas. É importante ressaltar que os profissionais da Eny Calçados envolvidos nessa ambiência da marca na internet apresentam maturidade profissional e enxergam que a inserção em um meio inovador não substitui a importância de divulgação em meios tradicionais, sendo visto como uma forma complementar de comunicação e não única.

O desafio da criação do conteúdo gerado e do acompanhamento do rápido crescimento das tecnologias continua existindo e, diariamente, os responsáveis pela inserção organizacional da Eny Calçados na web precisam estar envolvidos com essas tendências e antenados com todas as ações da concorrência, para que assim continuem tendo as respostas positivas que têm e também para que não fiquem para trás quanto às ações desenvolvidas.

Com relação à importância deste estudo para o campo da comunicação e das mídias sociais digitais, destaca-se que a observação, a análise e o entendimento do modo como se estabelece as estratégias comunicacionais no âmbito digital, possibilitam um melhor entendimento dos processos de interação e relacionamento entre empresas e cidadãos por meio da internet e das ferramentas nela disponíveis.

É válido ressaltar que foi difícil chegar ao tema da pesquisa e estabelecer os objetivos que seriam trabalhados no desenvolvimento, além de serem escassas as publicações de livros referentes ao assunto, tendo-se como base de pesquisa a própria internet e os artigos nela encontrados. Encerra-se aqui a "primeira etapa" deste trabalho, pois se acredita que futuros pesquisadores interessados em explorar e entender as estratégias de comunicação existentes nas mídias sociais podem dar prosseguimento ao assunto abordado, verificando as novas tendências que eventualmente surgirão.

\section{REFERÊNCIAS}

DUARTE, Jorge. Métodos e técnicas de pesquisa em comunicação. São Paulo: Autores Associados, 2005.

EXAME, Revista. Novos índices. Disponível em: < http://exame.abril.com.br/blogs/zeros-e -uns/page/3/> Acesso em: set 2011. 
FACEBOOK. Eny Calçados. Disponível em: <https://www.facebook.com/EnyCalcados > Acesso em: out 2011.

Facebook tem metade dos usuários do Orkut. Info Online. ONLINE, Info. Disponível em: <http://info.abril.com.br/noticias/internet/Facebook-ja-tem-metade-dos-usuarios-do -Orkut-31032011-12.shl> Acesso em: maio 2011.

FERREIRA, Francis H. G. Gestão do composto mercadológico. Disponível em: <http://www. biblioteca.sebrae.com.br/bds/bds.nsf/e88f72ba6056973403256d470064b9dc/dda8bc8358cd76a203256d520059b289/\$FILE/255_1_Arquivos_composto.pdf> Acesso em: set 2011

FORMSPRING. Eny Calçados. Disponível em <www.formspring.me/EnyCalcados> Acesso em: out 2011.

GIL, Antonio Carlos. Métodos e técnicas de pesquisa social. São Paulo: Atlas, 1991.

GROULX, A. C. Metodologia de pesquisa aplicado em áreas sociais. São Paulo: Atlas, 2010. HALLIDAY, Jean. Buick Builds Buzz for SUV On-, Off-Line. Advertising Age, 2003. Tradução livre disponível em: <http://www.unifra.br/professores/14306/SHIMP_Cap_01.pdf> Acesso em: agosto 2011.

IVO, Diego. Guia de redes sociais para as empresas. Disponível em: <http://www.primeirolugar.net/blog/redes-sociais-peq-medias-empresas.html> Acesso em: maio 2011.

JACCOUD, M. Perspectiva de observação como metodologia aplicada. São Paulo: Loyola, 2010.

LEAL, Renata. Twitter para as massas. Disponível em: < http://info.abril.com.br/corporate/ noticias/twitter-para-as-massas-24072009-0.shtml> Acesso em: out 2011.

MACHADO, Jones. Entrevista informal concedida à Carolina Ribeiro Pagliarini. Santa Maria: maio de 2011.

MARTINS, José Roberto. Branding: o manual para você criar, gerenciar e avaliar marcas. São Paulo: GlobalBrands, 2006.

MORAIS, Patricia. As redes sociais e os novos hábitos culturais dos consumidores na comunicação mercadológica do século XXI. Disponível em: < http://www.patriciamorais.com. br/2011/05/as-redes-sociais-e-os-novos-habitos.html> Acesso em: agosto 2011.

NIELSEN, Ibope. Ibope Nielsen Online. Disponível em: <http://www.ibope.com.br/calandra Web/servlet/CalandraRedirect?temp=5\&proj=PortallBOPE\&pub=T\&comp=Grupo+IBOPE\&$\mathrm{db}=\mathrm{caldb} \& d$ ocid=8C071AB5DCD38C2183256E890068EDFo > Acesso em: maio 2011.

OGDEN, James R.; CRESCITELLI, Edson. Comunicação integrada de marketing: conceitos, técnicas e práticas. São Paulo: Pearson Prentice Hall, 2007.

O QUE é um sistema de Gestão de Conteúdo. Paradigmas da internet. Disponível em: <http://www.paradigma.com.br/leiamais/leiamaisoo05/view> Acesso em: maio 2011.

Os Usuários do Twitter. Info Online. Disponível em: <http://info.abril.com.br/noticias/internet/dos-usuarios-do-Twitter-40-nunca-tuitaram-04022010-10.shl> Acesso em: maio 2011. 
OZAKI, Adalton M. Mercados eletrônicos: estratégias, inovação e um modelo para sua constituição. Coordenado por Eduardo Vasconcellos. São Paulo: Atlas, 2010.

PINHEIRO, Gabriela Rivas. Desgustando um novo canal de relacionamento com o consumidor: a gestão de conteúdo de marca via Twitter no case pizza hut. 2010. 6of. Trabalho final de graduação (Graduação em Publicidade e Propaganda) - Centro Universitário Franciscano, Santa Maria, 2010.

PRIMO, A. Interação mediada por computador: comunicação, cibercultura e cognição. Porto Alegre: Sulina, 2007.

RECUERO, Raquel. Redes sociais na internet. Disponível em: <http:/www.redessociais.net/ cubocc_redessociais.pdf> Acesso em: maio 2011.

REIS, Abel. Em entrevista concedida à Revista Info, versão impressa de Outubro de 2011. SCUSSEL, Israel. Entendendo redes sociais e mídias sociais assim como suas ferramentas. Disponível em: <http://midiassociais.blog.br/2010/02/23/redessociais-vs-midiassociais/> Acesso em: maio 2011.

SITE INSTITUCIONAL. Eny Calçados. Evolução da marca. Disponível em: <http://eny.com.br/ novo_site/index.php?MODULE=descricao_menu\&COD_MENU=034>Acesso em: maio 2011.

TELLES, André. A revolução das mídias sociais: Cases, Conceitos, Dicas e Ferramentas. São Paulo: M Books do Brasil Editora Ltda., 2010.

TERRA, Portal. Anos 90: o desenvolvimento da internet no Brasil. Disponível em: <http://tecnologia.terra.com.br/internet10anos/interna/o,,Ol541825-El5026,00.html> Acesso em: maio 2011.

TWITTER. Eny Calçados. Disponível em: <www.twitter.com/EnyCalcados> Acesso em: set 2011.

YIN, Robert K. Estudo de caso: planejamento e métodos. Porto Alegre: Bookman, 2001.

YOUTUBE. Eny Calçados. Disponível em: <www.youtube.com> Acesso em: out 2011.

ZILBER, Silvia Novaes; TAVARES, José da Cunha; FEI, Eduardo Nascimento. E-procurement: vantagem competitiva em suprimentos. Disponível em:

<ttp://www.ea.ufrgs.br/graduacao/disciplinas/adm01010/2007/Artigos\%20T1_1/Compras\%20 03.pdf> Acesso em: maio 2011.

RECEBIDO EM: 28/10/12

ACEITO PARA PUBLICAÇÃO: 14/11/12 


\section{Carolina Pagliarini}

Publicitária, formada pelo Centro Universitário Franciscano (UNIFRA).

\section{Fabrise de Oliveira Müller}

Mestre em Administração e Negócios pela Pontifícia Universidade Católica do Rio Grande do Sul (PUCRS), Professora substituta do Curso de Relações Públicas da Universidade Federal de Santa Maria (UFSM), Membro do Grupo de Pesquisa em Comunicação Institucional e Organizacional UFSM/CNPq. 